\title{
Hip fracture subtypes, duration of hospital stay and its association with co morbidities
}

\author{
Joji Krishnan ${ }^{1}$, Meera Shenoy. ${ }^{2}$, Raffic. ${ }^{3}$ \\ ${ }^{1,}$ (Assistant Professor,Department Of Orthopaedics, Sree Gokulam Medical College\&Research \\ Foundation, Trivandrum, Kerala, India) \\ ${ }^{2}$ (Consultant, Department Of Obstetrics And Gynaecology, Kerala Government Health Services, India) \\ 3 (Professor \&head, Department Of Orthopaedics, Sree Gokulam Medical College\&Research Foundation, \\ Trivandrum, Kerala, India)
}

\begin{abstract}
Hip fractures (neck of femur and trochanteric) are the most common osteoporotic fractures seen in the elderly, contributing to significant degrees of morbidity, mortality and limitations in quality of life. We have evaluated the patterns of hip fracture subtypes and its association to various risk factors. 273 subjects with hip fractures were studied; there was a small increase in proportion of neck fractures in men and trochanteric fractures in women with age, both fractures occurred more commonly in women than men. Trochanteric fractures were associated with long term steroid intake and asthma. Strong association was observed with co morbidities and the total duration of hospital stay, the pre operative and post operative hospital stay. Hence, by addressing the co morbidities that have the greatest impact on hospitalization, we may be able to lower the duration of hospitalization and thereby treatment costs.
\end{abstract}

Keywords: age, Co morbidities, Hip fracture subtypes, hospital stay, neck of femur, trochanteric fracture.

\section{Introduction}

Hip fractures (neck of femur and trochanteric) are the most common osteoporotic fractures seen in the elderly and contribute to significant degrees of morbidity, mortality and limitations in quality of life[1]. Hip fractures, of either type are diverse in its etiology and patterns of occurrence[2] left alone the differences in their anatomical structure and bony composition [3]. Graying India with an estimated 227 million of elder population in 2050 will be[4] a challenge for national infrastructures, particularly public health systems ; this poses a huge burden of hip fractures whose risk increases dramatically with age . Many publications have linked various factors such as age \& sex [5], racial differences [6],dietary factors[7],alcohol intake \&beverage preference[8], lifestyle \& drug intake[9][10], chronic renal disease[11],occupation [12],physical activity [13],rheumatoid arthritis \& steroid therapy[14],smoking[15] \& chronic illness[16] with the risk of trochanteric fractures and femoral neck fractures. However, the strength of association has not been established in most of the studies .Hence, we have evaluated the association of risk factors with the subtypes of hip fractures. We have further tried to look into the patterns of occurrence of hip fracture subtypes and its association with age and gender

\section{Materials and methods}

This is a retrospective analysis of data retrieved from the electronic data base of Sree Gokulam Medical college and Research Foundation, Trivandrum in southern India, a state with major epidemiological transition. 273 subjects with hip fractures (fracture neck of femur (ICD 10: S72.0-S72.091) and trochanteric fracture (ICD 10: S72.1-S72.191)) admitted and who had undergone surgical treatment in this institute between $1^{\text {st }}$ January 2011 and $31^{\text {st }}$ July 2014, were evaluated using a structured questionnaire containing the following variables : age ,gender , hip fracture types (NOF/TRO),presence or absence of co-morbidities such as diabetes mellitus, hypertension , renal dysfunction, chronic obstructive pulmonary disease, steroid intake, asthma, coronary artery disease , cerebrovascular accident and epilepsy. The duration of total hospital stay, the pre-operative period and post operative period in the hospital (in days); pre and post operative renal parameters, creatine, urea and sodium were also recorded. The outcomes were not evaluated and patients with malignant neoplasm were excluded from the study

\subsection{Statistical Analysis}

The distribution of anatomic hip fracture types as a function of age and gender was done after categorizing the participants into five age strata of $<50 \mathrm{yrs}, 50-59 \mathrm{yrs}$. 60-69yrs, 70-79yrs, $>80 \mathrm{yrs}$. Hip fracture types by age groups and gender, co morbidities, renal and metabolic parameters was analyzed by Chi- 
Square. Non parametric test of Mann Whitney was used for skewed data of duration of hospital stay in days (total hospital stay, the pre-operative period and post operative period) (SPSS for windows version 17)

Statistical significance was set at $<0.05$

\section{Results}

\subsection{Demographic profile}

We had 273 cases and the subtypes by sex and age group is given in table 1 and 2 and figure 1 and 2

Table 1. Hip fracture sub types and gender

\begin{tabular}{|c|c|c|c|c|c|c|c|}
\hline \multirow[b]{3}{*}{ Gender } & \multicolumn{4}{|c|}{ Type of fracture } & \multirow{2}{*}{\multicolumn{2}{|c|}{ Total }} & \multirow[t]{2}{*}{$\chi^{2}(\mathbf{p})$} \\
\hline & \multicolumn{2}{|c|}{$\overline{\text { Neck of femur }}$} & \multicolumn{2}{|c|}{ Trochanteric } & & & \\
\hline & $\overline{\mathrm{N}}$ & $\%$ & $\overline{\mathrm{N}}$ & $\overline{\%}$ & $\mathrm{~N}$ & $\%$ & 1.534 \\
\hline Male & 35 & 28.9 & 34 & 22.4 & 69 & 25.3 & $(0.216)$ \\
\hline Female & 86 & 71.1 & 118 & 77.6 & 204 & 74.7 & \\
\hline Total & 121 & 100 & 152 & 100 & 273 & 100 & \\
\hline
\end{tabular}

Table 2. Hip fracture sub types and age distribution

\begin{tabular}{|c|c|c|c|c|c|c|}
\hline \multicolumn{7}{|c|}{ Neck of Femur } \\
\hline \multirow[t]{2}{*}{ Age } & \multicolumn{2}{|c|}{ Male } & \multicolumn{2}{|c|}{ Female } & \multicolumn{2}{|c|}{ Total } \\
\hline & $\mathrm{N}$ & $\%$ & $\mathrm{~N}$ & $\%$ & $\mathrm{~N}$ & $\%$ \\
\hline$<\mathbf{5 0}$ & 4 & 11.4 & 3 & 3.5 & 7 & 5.8 \\
\hline $50-59$ & 4 & 11.4 & 4 & 4.7 & 8 & 6.6 \\
\hline $60-69$ & 7 & 20 & 17 & 19.8 & 24 & 19.8 \\
\hline 70-79 & 11 & 31.4 & 33 & 38.4 & 44 & 36.4 \\
\hline$>80$ & 9 & 25.7 & 29 & 33.7 & 38 & 31.4 \\
\hline \multicolumn{7}{|c|}{ Trochanteric } \\
\hline \multirow[t]{2}{*}{ Age } & \multicolumn{2}{|c|}{ Male } & \multicolumn{2}{|c|}{ Female } & \multicolumn{2}{|c|}{ Total } \\
\hline & $\mathrm{N}$ & $\%$ & $\mathrm{~N}$ & $\%$ & $\mathrm{~N}$ & $\%$ \\
\hline$<\mathbf{5 0}$ & 5 & 14.7 & 1 & 0.8 & 6 & 3.9 \\
\hline $50-59$ & 7 & 20.6 & 2 & 1.7 & 9 & 5.9 \\
\hline $60-69$ & 4 & 11.8 & 22 & 18.6 & 26 & 17.1 \\
\hline 70-79 & 8 & 23.5 & 44 & 37.3 & 52 & 34.2 \\
\hline$>80$ & 10 & 29.4 & 49 & 41.5 & 59 & 38.8 \\
\hline
\end{tabular}

Figure 1. Fracture neck of femur by gender and age

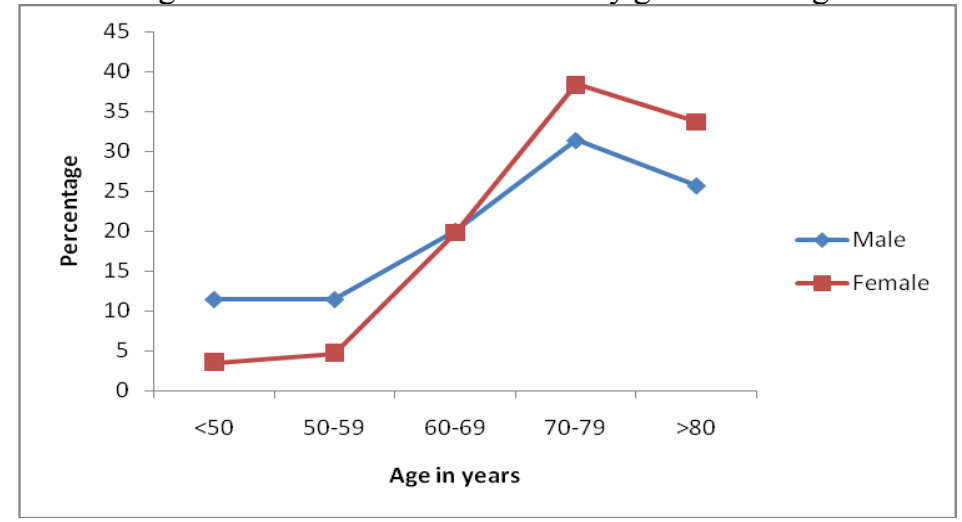


Figure 2. Trochanteric fracture by gender and age

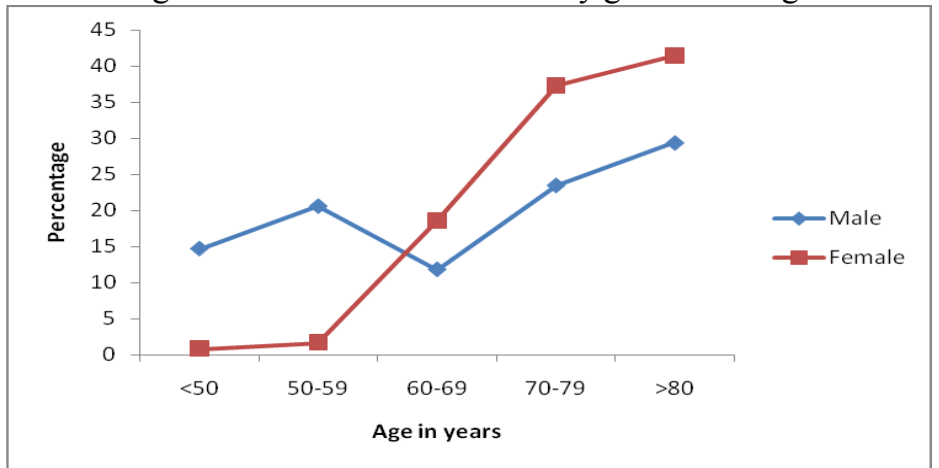

\subsection{Rate ratios of sub types of hip fracture}

A rate ratio of trochanteric to neck of femur fractures by age groups and gender is shown in Table 3 and Figure 3. A steady increase is noted among females across the age groups from $<50$ to the older age. In male, there is an increased ratio in the age group till 59 years and later there is a decline till age 79.

Table 3. Rate ratios of trochanteric to neck of femur fractures by age groups and gender

\begin{tabular}{|l|l|l|}
\hline \multicolumn{2}{|c|}{ Rate ratio } \\
\hline Age groups in years & $\underline{\text { Male }}$ & Female \\
\hline$<50$ & 1.25 & 0.333 \\
\hline $50-59$ & 1.75 & 0.5 \\
\hline $60-69$ & 0.571 & 1.29 \\
\hline $70-79$ & 0.727 & 1.333 \\
\hline$>80$ & 1.11 & 1.69 \\
\hline
\end{tabular}

Figure 3. Rate ratios of trochanteric to neck of femur fractures by age groups and gender

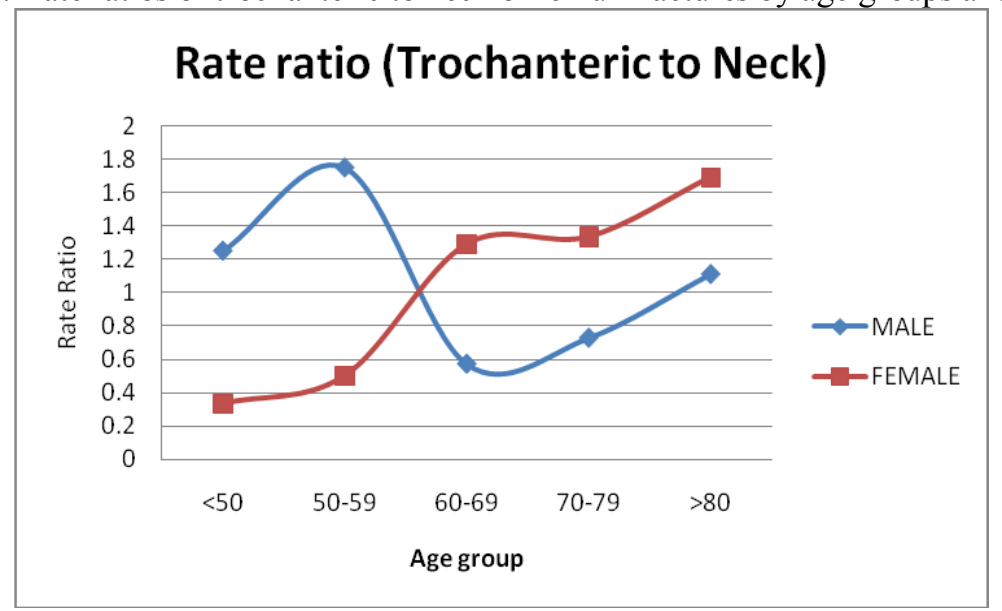

\subsection{Comorbidities and fracture sub types}

The association of comorbidities to the sub types of fracture is given in Table 4. There was no association observed in most of the diseases except in those with bronchial asthma. Among those with asthma, the association was strong $(8.6 \%$ in trochanteric versus $1.7 \%$ in neck of femur: $p=0.013)$. Steroid intake was associated in those with trochanteric fractures $(7.9 \%)$ compared to neck of femur $(2.5 \%$ : $\mathrm{p}=0.051)$ 
Table 4. Co-morbidities and their association with hip fracture types

\begin{tabular}{|c|c|c|c|c|c|c|c|c|}
\hline & & \multicolumn{4}{|c|}{ Fracture type } & \multirow{2}{*}{\multicolumn{2}{|c|}{$\underline{\text { Total }}$}} & \multirow{3}{*}{$\chi^{2}$ ( p value) } \\
\hline & & \multicolumn{2}{|c|}{ Neck of femur } & \multicolumn{2}{|c|}{ Trochanteric } & & & \\
\hline & & $\mathrm{N}$ & $\%$ & $\mathrm{~N}$ & $\%$ & $\mathrm{~N}$ & $\%$ & \\
\hline \multirow{2}{*}{$\begin{array}{l}\text { Any } \\
\text { disease }\end{array}$} & Yes & 84 & 69.4 & 109 & 71.7 & 193 & 70.7 & \multirow[t]{2}{*}{$0.170(p=0.680)$} \\
\hline & No & 37 & 30.6 & 43 & 28.3 & 80 & 29.3 & \\
\hline \multirow[t]{2}{*}{$\mathrm{DM}^{*}$} & Yes & 53 & 43.8 & 67 & 44.1 & 120 & 44 & \multirow{2}{*}{$\begin{array}{l}0.002 \\
(p=0.963)\end{array}$} \\
\hline & No & 68 & 56.2 & 85 & 55.9 & 153 & 56 & \\
\hline \multirow[b]{2}{*}{ HTN** } & Yes & 57 & 47.1 & 74 & 48.7 & 131 & 48 & \multirow[t]{2}{*}{$0.067 \quad 0.796$} \\
\hline & No & 64 & 52.9 & 78 & 51.3 & 142 & 52 & \\
\hline \multirow{2}{*}{$\begin{array}{l}\text { Renal } \\
\text { Disease }\end{array}$} & Yes & 7 & 5.8 & 7 & 4.6 & 14 & 5.1 & \multirow[t]{2}{*}{$0.193(0.661)$} \\
\hline & No & 114 & 94.2 & 145 & 95.4 & 259 & 94.9 & \\
\hline \multirow{2}{*}{$\begin{array}{l}\text { Hepatic } \\
\text { disease }\end{array}$} & Yes & 0 & 0 & 1 & 0.7 & 1 & 0.4 & \multirow[t]{2}{*}{$0.799 \quad(0.371)$} \\
\hline & No & 121 & 100 & 151 & 99.3 & 272 & 99.6 & \\
\hline \multirow{2}{*}{ COPD\# } & Yes & 10 & 8.3 & 11 & 7.2 & 21 & 7.7 & \multirow[t]{2}{*}{$0.100(0.752)$} \\
\hline & No & 111 & 91.7 & 141 & 92.8 & 252 & 92.3 & \\
\hline \multirow{2}{*}{$\begin{array}{l}\text { Steroid } \\
\text { intake }\end{array}$} & Yes & 3 & 2.5 & 12 & 7.9 & 15 & 5.5 & \multirow[t]{2}{*}{$3.805(0.051)$} \\
\hline & No & 118 & 97.5 & 140 & 92.1 & 258 & 94.5 & \\
\hline \multirow{2}{*}{ Asthma } & Yes & 2 & 1.7 & 13 & 8.6 & 15 & 5.5 & \multirow[t]{2}{*}{$6.177(0.013)$} \\
\hline & No & 119 & 98.3 & 139 & 91.4 & 258 & 94.5 & \\
\hline \multirow{2}{*}{ CAD\#\# } & Yes & 9 & 7.4 & 13 & 8.6 & 22 & 8.1 & \multirow[t]{2}{*}{$0.113(0.737)$} \\
\hline & No & 112 & 92.6 & 139 & 91.4 & 251 & 91.9 & \\
\hline \multirow{2}{*}{ CVA\#\#\# } & Yes & 12 & 9.9 & 25 & 16.4 & 37 & 13.6 & \multirow[t]{2}{*}{$2.452(0.117)$} \\
\hline & No & 109 & 90.1 & 127 & 83.6 & 236 & 86.4 & \\
\hline \multirow{2}{*}{ Epilepsy } & Yes & 7 & 5.8 & 5 & 3.3 & 12 & 4.4 & \multirow[t]{2}{*}{$0.998(0.318)$} \\
\hline & No & 114 & 94.2 & 147 & 96.7 & 261 & 95.6 & \\
\hline
\end{tabular}

Abbreviations: *DM diabetes mellitus; **HTN Hypertension; COPD\# chronic obstructive pulmonary disease; \#\# CAD Coronary artery disease; \#\#\# CVA Cerebro vascular accidents

\subsection{Duration of hospital stay}

Duration of total hospital stay, pre operative and postoperative stay in days and co morbidity with hip fracture is depicted in Table 5. The median duration of total hospital stay; pre operative and postoperative stay is significantly more in those with any morbidity.

Table 5. Duration of total hospital stay, pre operative and postoperative stay in days and comorbidity with hip fracture

\begin{tabular}{|c|c|c|c|c|c|c|c|c|c|}
\hline \multirow[t]{2}{*}{ Comorbidities } & \multirow[t]{2}{*}{$\mathbf{N}$} & \multicolumn{8}{|c|}{ Duration of total hospital stay (days) } \\
\hline & & Mean & sd & Minimum & $\begin{array}{l}\text { First } \\
\text { quartile }\end{array}$ & Median & $\begin{array}{l}\text { Third } \\
\text { quartile }\end{array}$ & Maximum & $\begin{array}{l}\text { Mann- } \\
\text { Whitney }\end{array}$ \\
\hline Yes & 193 & 13.6 & 4.2 & 2.0 & 11.0 & 13.0 & 16.0 & 28.0 & \multirow[t]{2}{*}{$\mathrm{P}<0.001$} \\
\hline No & 80 & 11.0 & 3.6 & 5.0 & 8.0 & 10.5 & 13.0 & 21.0 & \\
\hline \multicolumn{10}{|c|}{ Duration of Pre OP hospital stay } \\
\hline Yes & 193 & 3.8 & 2.1 & 1.0 & 2.0 & 4.0 & 5.0 & 13.0 & \multirow[t]{2}{*}{$<0.003$} \\
\hline No & 80 & 3.0 & 1.4 & 1.0 & 2.0 & 2.0 & 4.0 & 7.0 & \\
\hline \multicolumn{10}{|c|}{ Duration of Post OP hospital stay } \\
\hline Yes & 193 & 9.7 & 3.6 & 1.0 & 7.0 & 10.0 & 12.0 & 22.0 & \multirow[t]{2}{*}{$<0.001$} \\
\hline No & 80 & 8.0 & 3.2 & 3.0 & 6.0 & 7.0 & 10.0 & 18.0 & \\
\hline
\end{tabular}

\section{Discussion}

In this study of 273 subjects with hip fracture sub types, we observed no association between the subtypes and gender. The gender distribution is in agreement with the published reports of increased occurrence of both the fracture patterns in women than in men [2], [5], [17], [18]. The frequency of neck of femur fractures were greater than that of trochanteric fractures during a limited period of time, in the peri menopausal period for women and in elderly males ( $>60$ yrs). This was in concordance with the 15 published reports by Baudoin et al[19]. The rate ratio (of trochanteric to neck of femur fractures) increased steadily in women with a steep increase in the immediate post menopausal period whereas in males, there was a steep decrease in the phase corresponding to steep increase in women. The rate ratio in our study touched unity at around the age of 60 in men and women in contrast to the age of 75-85 in the US population [5]. A small increase in proportion of neck fractures in men and trochanteric fractures in women with age is consistent with the observations of Tanner et $\mathrm{al}[2]$ and Karagas et al and [20]. This difference may be due to the fact that in ages between 60-75, women loose 
bone from all sites of the skeleton with maximum loss in trochanteric region in contrast to men who lose only minimally at the trochanteric region, and gained bone mass at the Ward's triangle over the period [21]. Other reason could be perhaps with increasing age, there is a tendency to fall, and that too in a different way [22]. Fall onto the greater trochanter is a phenomenon of old age and it has been shown that the lateral fall onto the greater trochanter is particularly difficult to protect oneself during the fall [23-25].

There was no association with co morbidities to any particular fracture pattern except in those with bronchial asthma $(\mathrm{p}=0.013)$ and prolonged steroid intake $(\mathrm{p} .051)$ and trochanteric fractures. The stronger association with asthma could be due to osteoporotic risk factors pertinent to asthmatic patients [26], [27] which could be related to medications/lifestyle/genetic/associated endocrine or associated chronic disorders. There was small increase in hypertension and coronary artery disease in trochanteric fractures; however, this was not statistically significant.

There was a strong association between the co-morbidities and the total duration $(\mathrm{p}<.001)$, pre operative $(\mathrm{p}<.003)$ and postoperative hospital stay $(\mathrm{p}<.001)$. This is similar to the study of Chen et al [28] suggesting that higher co morbidities in hip fractures incurred higher hospitalization costs as well. Hence, by addressing the co morbidities, we may be able to lower the duration of hospitalization and thereby treatment costs by better managing co morbidities that have the greatest impact on hospitalization costs.

We would like to address some of the limitations in this study. The sample size was smaller and this being a retrospective analysis, we did not evaluate the complications or functional outcome of subjects, In addition, this is a single centre study in a tertiary hospital and hence limits its external validity. The costing of treatment and the post discharge chronic care costs have not been obtained. Since there is an association of duration of stay and co morbidities, there is a scope economic analysis for the incremental cost for the morbidities; this study may serve as a model for future prospective studies with costing and functional status.

\section{References}

[1] Johnell O , Kanis J , "Epidemiology of osteoporotic fractures,” Osteoporos. Int. J. Establ. Result Coop. Eur. Found. Osteoporos. Natl. Osteoporos. Found. USA, vol. 16 Suppl 2, pp. S3-7, Mar. 2005.

[2] Tanner D A, Kloseck M, Crilly R G, Chesworth B , Gilliland J, "Hip fracture types in men and women change differently with age," BMC Geriatr., vol. 10, no. 1, p. 12, Mar. 2010.

[3] Riggs B L, Wahner H W, Seeman E, Offord K P, Dunn W L, Mazess R B, Johnson K A, Melton L J , "Changes in bone mineral density of the proximal femur and spine with aging. Differences between the postmenopausal and senile osteoporosis syndromes," J. Clin. Invest., vol. 70, no. 4, pp. 716-723, Oct. 1982.

[4] N. I. on Aging, "Humanity's Aging," National Institute on Aging, 26-Mar-2012. [Online]. Available: http://www.nia.nih.gov/research/publication/global-health-and-aging/humanitys-aging. [Accessed: 29-Oct-2014].

[5] Karagas M R , Lu-Yao G L , Barrett J A, Beach M L, Baron J A, "Heterogeneity of Hip Fracture: Age, Race, Sex, and Geographic Patterns of Femoral Neck and Trochanteric Fractures among the US Elderly," Am. J. Epidemiol., vol. 143, no. 7, pp. 677-682, Apr. 1996.

[6] Hochberg M C , "Racial Differences in Bone Strength,” Trans. Am. Clin. Climatol. Assoc., vol. 118, pp. 305-315, 2007.

[7] "Dietary Factors and the Incidence of Hip Fracture in Middle-aged Norwegians." [Online]. Available: http://aje.oxfordjournals.org/content/145/2/117.short. [Accessed: 24-May-2014].

[8] Høidrup S , Grønbæk M , Gottschau A , Lauritzen J B , Schroll M, "Alcohol Intake, Beverage Preference, and Risk of Hip Fracture in Men and Women,” Am. J. Epidemiol., vol. 149, no. 11, pp. 993-1001, Jun. 1999.

[9] "Association of Race and Other Potential Risk Factors with Nonvertebral Fractures in Community-dwelling Elderly Women." [Online]. Available: http://aje.oxfordjournals.org/content/149/11/1002.short. [Accessed: 24-May-2014].

[10] Weiland S K, Rūckmann A, Keil U, Lewis M, Dennler H J, Welzel D, "Thiazide diuretics and the risk of hip fracture among 7079 year old women treated for hypertension,” Eur. J. Public Health, vol. 7, no. 3, pp. 335-340, Sep. 1997.

[11] West S L, Lok C E, Jamal S A, "Fracture Risk Assessment in Chronic Kidney Disease, Prospective Testing Under Real World Environments (FRACTURE): a prospective study," BMC Nephrol., vol. 11, no. 1, p. 17, Aug. 2010.

[12] Suen L K P, "Occupation and risk of hip fracture," J. Public Health, vol. 20, no. 4, pp. 428-433, Dec. 1998

[13] Farahmand B Y, Persson P G ,Michaëlsson, Baron K J A, Alberts A, Moradi T, Ljunghall S, "Physical activity and hip fracture: a population-based case-control study,” Int. J. Epidemiol., vol. 29, no. 2, pp. 308-314, Apr. 2000.

[14] Cooper C , Coupland C, Mitchell M, "Rheumatoid arthritis, corticosteroid therapy and hip fracture.," Ann. Rheum. Dis., vol. 54, no. 1, pp. 49-52, Jan. 1995.

[15] "Tobacco smoking and risk of hip fracture in men and women." [Online]. Available: http://ije.oxfordjournals.org/content/29/2/253.short. [Accessed: 24-May-2014].

[16] Grisso J A, Kelsey J L, O’Brien L A, Miles CG, Sidney S, Maislin G, LaPann K, Moritz D, Peters B, "Risk Factors for Hip Fracture in Men," Am. J. Epidemiol., vol. 145, no. 9, pp. 786-793, May 1997.

[17] Hinton R Y, Lennox D W, Ebert F R, Jacobsen S J , Smith G S , "Relative rates of fracture of the hip in the United States. Geographic, sex, and age variations," J. Bone Joint Surg. Am., vol. 77, no. 5, pp. 695-702, May 1995.

[18] Baron J A, Barrett J, Malenka D, Fisher E, Kniffin W, Bubolz T, Tosteson T, "Racial differences in fracture risk," Epidemiol. Camb. Mass, vol. 5, no. 1, pp. 42-47, Jan. 1994.

[19] Baudoin C ,Fardellone P, Sebert J L, "Effect of sex and age on the ratio of cervical to trochanteric hip fracture. A meta-analysis of 16 reports on 36,451 cases," Acta Orthop. Scand., vol. 64, no. 6, pp. 647-653, Dec. 1993.

[20] Karagas M R , Lu-Yao GL, Barrett J A, Beach M L, Baron J A, "Heterogeneity of Hip Fracture: Age, Race, Sex, and Geographic Patterns of Femoral Neck and Trochanteric Fractures among the US Elderly," Am. J. Epidemiol., vol. 143, no. 7, pp. 677-682, Apr. 1996.

[21] Dennison E, Eastell R, Fall C H, Kellingray S, Wood P J, Cooper C, "Determinants of bone loss in elderly men and women: a prospective population-based study," Osteoporos. Int. J. Establ. Result Coop. Eur. Found. Osteoporos. Natl. Osteoporos. Found. USA, vol. 10, no. 5, pp. 384-391, 1999. 
[22] Talbot L A, Musiol R J, Witham E K, Metter E J, "Falls in young, middle-aged and older community dwelling adults: perceived cause, environmental factors and injury," BMC Public Health, vol. 5, p. 86, 2005.

[23] van den Kroonenberg A J, Hayes W C, McMahon T A, "Hip impact velocities and body configurations for voluntary falls from standing height," J. Biomech., vol. 29, no. 6, pp. 807-811, Jun. 1996.

[24] Crilly R G, Tanner D A, Kloseck M, Chesworth BM, "Hip Fractures in Long-Term Care: Is the Excess Explained by the Age and Gender Distribution of the Residents?,” J. Aging Res., vol. 2010, Aug. 2010.

[25] Hayes W C, Myers E R, Robinovitch S N, Van Den Kroonenberg A, Courtney A C, McMahon T A, "Etiology and prevention of age-related hip fractures," Bone, vol. 18, no. 1 Suppl, p. 77S-86S, Jan. 1996.

[26] "Asthma: Comorbidities, Coexisting Conditions, and Differential Diagnosis - Google Books." [Online]. Available: http://books.google.co.in/books?id=0Do_AwAAQBAJ\&pg=PA352\&lpg=PA352\&dq=Asthma+and +hip+fractures\&source=bl\&ots= 153svr3fKe\&sig=fwSJplj2I31LJDeG De5OjgyE3U\&hl=en\&sa=X\&ei=LXxUVO3PBMGiugT -

1 YL4AQ\&ved=0CD4Q6AEwBA\#v=onepage \&q=Asthma\%20and\%20hip\%20fractures\& $\mathrm{f}=$ false. [Accessed: 01 -Nov-2014].

[27] “Asthma Drugs Boost Hip Fracture Risk." [Online]. Available: http://www.webmd.com/asthma/news/20021212/asthma-drugsboost-hip-fracture-risk. [Accessed: 26-Oct-2014].

[28] "Hip Fractures in the Elderly The Impact of Comorbid Illnesses on," Docstoc.com. [Online]. Available: http://www.docstoc.com/docs/84531917/Hip-Fractures-in-the-Elderly-The-Impact-of-Comorbid-Illnesses-on. [Accessed: 01-Nov2014]. 